\title{
ESTUDO DA TAXOCENOSE DE CHRYSOPIDAE (INSECTA, NEUROPTERA) NA RESERVA BIOLÓGICA DE SOORETAMA, ES.
}

\author{
Thais Berçot Pontes Teodoro ${ }^{1}$ \\ Gilberto Soares Albuquerque ${ }^{2}$
}

Resumo: O objetivo deste trabalho foi descrever a taxocenose de Chrysopidae na Reserva Biológica de Sooretama durante um ano de estudo. Esta Reserva é uma unidade de conservação situada no Espírito Santo, cuja importância reside na diversidade da fauna e flora e na representatividade da Mata Atlântica de Tabuleiros. Foram amostrados três locais (borda preservada, borda não preservada e interior da mata), empregando-se dois métodos de coleta: rede entomológica e armadilha atrativa. Foram capturados 1.821 adultos, distribuídos em 30 morfoespécies. Não houve dominância marcante entre as espécies mais abundantes, de forma que a equitabilidade entre elas foi grande. Os valores de diversidade (Shannon) e riqueza (Margalef) foram elevados, em comparação com os obtidos para taxocenoses de Chrysopidae em outras áreas do Brasil. A diversidade da taxocenose foi maior no interior da mata, seguido da área de borda preservada e da borda menos preservada.

Palavras-chave: Crisopídeos; Ecologia; Mata Atlântica; Mata de Tabuleiros.

\footnotetext{
${ }^{1}$ Ciências Biológicas/Universidade Estadual Norte Fluminense, Brasil. E-mail: thaisbercpt@yahoo.com.br.

2 Ciências Biológicas/Universidade Estadual Norte Fluminense, Brasil. E-mail: gsa@uenf.br.
} 